\title{
OUTCOME OF IMPLEMENTING SURGICAL SAFETY CHECKLIST IN PEDIATRIC SURGERY IN TERTIARY LEVEL HOSPITAL
}

\author{
Bajracharya $J^{1}$ Shrestha $R_{,}{ }^{1}$ Joshi $H R^{2}$, Adhikari $R P^{3}$
}

${ }^{1}$ Pediatric Surgery Unit, Department of Surgery, ${ }^{2}$ Department of Anaesthesiology, ${ }^{3}$ Department of Microbiology, Nepal Medical College Teaching Hospital, Kathmandu, Nepal

\begin{abstract}
The World Health Organization (WHO) implemented the Surgical Safety Checklist (SSCL) as a part of Safe Surgery Saves Lives campaign. Even after 12 years of implementation of WHO SSCL, available literature is still lacking from developing countries, where the potentially greatest impact could have been observed. A prospective randomized controlled trial done in Tertiary level hospital from September 2018 - February 2020 enrolled pediatric patients aged 0 day to 15 years. The patients were randomly allocated into groups by lottery as Group A - control and Group B - Intervention group. Group A was given the basic pre-operative care. Group B were enrolled in the safety checklist. The data were collected in the printed forms and analyzed. The patients were followed for surgical site infections (SSI). Compliance of the safety checklist was assessed with completion of the checklist fully or partially. Total cases enrolled were 310 with 155 in each group. Age of patients ranged from 1 day to 15 years. SSI was present in 35 patients in group A and 29 patients in group B. The Outcome of implementation of SSC on appearance of SSI was not significant. SSI was decreased on checklist implementation with OR of 0.78 (95\% CI 0.45 - 1.37). Outcome of SSC compliance shown by OR was 0.39 (95\% CI $0.15-0.99)$. Use of SSCL decreases the postoperative complications and improves the outcome. Compliance is the key to success of the implementation of the checklist.
\end{abstract}

\section{KEYWORDS}

Surgical Safety Checklist, Surgical Site Infection, Compliance

\section{CORRESPONDING AUTHOR}

Dr. Jasmine Bajracharya,

Lecturer,

Pediatric Surgery Unit, Department of Surgery

Nepal Medical College Teaching Hospital,

Attarkhel, Gokarneshwor-8, Kathmandu, Nepal

Email: jas20005@hotmail.com

Orcid No: https://orcid.org/0000-0002-9100-2102

DOI: https://www.doi.org/10.3126/nmcj.v23i1.36230 


\section{INTRODUCTION}

The evidence and theoretical frameworks for improving surgical outcomes by WHO Surgical Safety Checklist (SSC) for successful implementation in low-income countries remain lacking. ${ }^{1}$ An average of 1.5 billion surgeries are performed each year according to data from WHO, which indicate that one of every 25 people undergoes an operation in a given year. Studies which examine the causes of wrong-site surgeries suggest, the lack of communication among the surgical team members, as the main cause for these error. ${ }^{2}$ The Safe Surgery Saves Lives Project was initiated by World Alliance for Patient Safety in June 2008, which increased the legal liability to raise awareness about patient care safety and reduce the number of deaths caused by surgeries worldwide. ${ }^{3}$

Compliance remains a major problem in implementation of checklist, despite its effectiveness in increasing patient safety and also causes gaps in its daily use till date. $^{4} \quad$ Research has suggested that barriers to implementation of the SSC include staff hierarchy, time constraints, inconsistent delivery with omission of items. ${ }^{5}$ Viewing the checklist as a tick box exercise and nobody assuming responsibility for sign-out checks lead to its omission. ${ }^{5}$ Making the SSC mandatory does not lead to the expected outcome of reducing risks for patients and non-adhering to internal guidelines is seen to be a commonly accepted practice. ${ }^{6}$ The benefits of the checklist have been elaborated in various research articles. Various studies have been done on why there is no compliance in spite of those benefits.

Studies indicate that when all stages of the checklist are completed, $14 \%$ of complications can be prevented, and odds of experiencing a complication reduce by up to $43 \% .^{7}$ A study by Vries et al had shown that the use of a checklist leads to better compliance with regard to the timing of antibiotic prophylaxis administration leading to better control of SSIs. ${ }^{8}$ WHO checklist is generally considered to be one of the evidence based procedures to prevent postoperative surgical infections. ${ }^{9}$ Timely antibiotic administration is linked to decrease in surgical site infection. ${ }^{10}$ Classen found that the use of antibiotics within the 2-hour period before an operation was associated with the lowest rate of surgical wound infection. Patients who received their antibiotics more than 2 hours before surgery also had a high rate of wound infection. ${ }^{11}$ Antibiotics are often administered too early, too late, or simply erratically during peri-operative period, in both developed and developing countries, which make them ineffective in reducing patient harm. ${ }^{12}$ The greatest risk reduction occurred when antibiotics were administered between 30 and 60 minutes prior to the incision. ${ }^{13}$

Current study is an attempt to evaluate the outcome of the implementation of the checklist by monitoring the compliance to the checklist and rate of SSI in our scenario.

\section{MATERIALS AND METHODS}

This is a prospective randomized controlled trial approved by Research \& Institutional Review Committee (IRC) of Nepal Medical College, Kathmandu Nepal on $10^{\text {th }}$ September 2018 conducted from September 2018 - February 2020. All the pediatric patients aged 0 day to 15 years enrolled to operate in the Pediatric Surgery Unit were included in the study. The patients were randomly allocated into control and intervention groups by lottery. Group A is control group which was taken for operation according to the routine steps. They were given the basic pre-operative care and the basic data of the patient and the procedures were recorded in a printed form. Group B, the intervention group, was enrolled in the safety checklist. All the points in the checklist were followed from sign in (before induction of anaesthesia), time out (before skin incision) and sign out (before patient leaves operating room). The data were collected in the printed form (preforma). The patients were followed for surgical site infections (SSI). All the data were recorded for each case enrolled. Compliance of the safety checklist was assessed with completion of the checklist fully or partially. SSC and the questionnaire filled during the surgery by floor nurse were collected and analyzed later. Patients were followed after surgery, at the time of discharge, follow up in outdoor and after 30 days of surgery for SSI. The compliance to the checklist was analyzed with the extent of completion of SSC. Data was collected, entered and analysed in computer. The statistical analysis was conducted using SPSS (Statistical package for social science) version 16 statistical software.

\section{RESULTS}

From September 2018 to February 2020 total number of cases enrolled was 310 with 155 in each group. Age of patients ranged from 1 day to 15 years. Mean age was 6.8 years. Baseline variables are shown in table 1 . Surgical site infection was present in 35 patients in group 
A and 29 patients in group B. The outcome of implementation of SSC on appearance of SSI was as shown by Chi Square test was 0.70 which was not significant (P value of 0.40 ). SSI was decreased on checklist implementation with odds ratio of $0.78(0.45-1.37$ at $95 \% \mathrm{CI})$. Outcome of SSC compliance shown by odds ratio was 0.39 (95\% CI $0.15-0.99)$. SSI observed in emergency and elective cases were analyzed separately to reduce confounding bias. It was found that the odds of SSI was 1.06 (95\% CI: $0.46-2.43) \mathrm{P}$ value 0.53 for emergency cases and odds were 0.68 (95\% CI: 0.27 - 1.6) P value 0.27 for elective cases which was not significant as $\mathrm{P}>0.05$. Differences seen in compliance in emergency and elective cases was highly significant as $\mathrm{P}$ value obtained with chi square test was 0.01 with OR of 0.22 (95\% CI: $0.09-$ $0.52)$.

\begin{tabular}{|c|c|c|c|c|}
\hline \multicolumn{2}{|l|}{ Parameters } & Group A & Group B & $P$ value \\
\hline \multicolumn{2}{|c|}{ Age(Mean \pm SD) in years } & $7.67 \pm 4.7$ & $7.876 \pm 4.78$ & 0.71 \\
\hline & $<28$ days & 5 & 6 & \\
\hline & $1 \mathrm{mth}-1 \mathrm{yr}$ & 23 & 5 & \\
\hline \multirow[t]{3}{*}{ Age group } & $1-5 y r s$ & 42 & 54 & 0.009 \\
\hline & $5-12$ & 63 & 69 & \\
\hline & $>12$ & 22 & 21 & \\
\hline \multirow{2}{*}{ Gender } & Male & 109 & 126 & \multirow{2}{*}{0.03} \\
\hline & Female & 46 & 29 & \\
\hline \multirow{2}{*}{ Type of Operation } & Emergency & 72 & 36 & \multirow{2}{*}{0.001} \\
\hline & Elective & 83 & 119 & \\
\hline \multirow{7}{*}{ Wound Type } & Major & 45 & 44 & \multirow[b]{3}{*}{0.002} \\
\hline & Intermediate & 48 & 75 & \\
\hline & Minor & 62 & 36 & \\
\hline & Clean & 56 & 83 & \multirow{4}{*}{0.007} \\
\hline & Clean contaminated & 29 & 24 & \\
\hline & Contaminated & 55 & 43 & \\
\hline & Dirty & 15 & 5 & \\
\hline
\end{tabular}

\begin{tabular}{|c|c|c|c|}
\hline SSI & $\begin{array}{l}\text { Group A } \\
\text { (control) }\end{array}$ & $\begin{array}{c}\text { Group B } \\
\text { (intervention) }\end{array}$ & P value \\
\hline Yes & $35(22.5 \%)$ & $29(18.7 \%)$ & \multirow{2}{*}{0.40} \\
\hline No & $120(77.4 \%)$ & $126(81.2 \%)$ & \\
\hline \multicolumn{4}{|c|}{$\begin{array}{c}\text { Chi Square test }-\mathrm{P}<0.05 \text { significant (asym two } \\
\text { sided) }\end{array}$} \\
\hline \multicolumn{4}{|c|}{ Odds Ratio $=0.78(95 \%$ CI $0.45-1.37)$} \\
\hline
\end{tabular}

\begin{tabular}{|c|c|c|c|}
\hline \multirow{2}{*}{ Compliance } & \multicolumn{2}{|c|}{ SSI } & \multirow{2}{*}{ P value } \\
\hline & Yes & No & \\
\hline Full & $20(68.9 \%)$ & $107(84.9 \%)$ & \multirow{2}{*}{0.045} \\
\hline Partial & $9(31.1 \%)$ & $19(15.1 \%)$ & \\
\hline \multicolumn{4}{|c|}{ Chi Square test $-\mathrm{P}<0.05$ significant } \\
\hline
\end{tabular}

Table 4: Comparing SSI between two groups based on type of operation

\begin{tabular}{|c|c|c|c|c|c|c|c|}
\hline \multirow{2}{*}{\multicolumn{3}{|c|}{ Type of operation }} & \multicolumn{2}{|c|}{ SSI } & \multirow{2}{*}{ Total } & \multirow{2}{*}{ P value } & \multirow{2}{*}{ OR (at 95\% CI) } \\
\hline & & & yes & no & & & \\
\hline \multirow{3}{*}{ Emergency } & & Group A & 27 & 45 & 72 & & \\
\hline & Group & Group B & 13 & 23 & 36 & 0.53 & $1.06(0.46-2.43)$ \\
\hline & Total & & 40 & 68 & 108 & & \\
\hline \multirow[t]{3}{*}{ Elective } & $C r$ & Group A & 8 & 75 & 83 & & \\
\hline & Gr & Group B & 16 & 103 & 119 & 0.27 & $0.68(0.27-1.6)$ \\
\hline & Total & & 24 & 178 & 202 & & \\
\hline
\end{tabular}

Chi Square test $-\mathrm{P}<0.05$ significant 
Table 5: Compliance to SSC based on Type of Surgery

\begin{tabular}{|lccccc|}
\hline Type of operation & \multicolumn{2}{c}{ Compliance } & Total & P value & OR (at 95\% CI) \\
Emergency & Full & Partial & & & \\
Elective & 23 & 14 & 37 & & $0.22(0.09-0.52)$ \\
Total & 104 & 14 & 118 & & \\
\hline
\end{tabular}

Chi Square test $-\mathrm{P}<0.05$ significant

\section{DISCUSSION}

WHO checklist is generally considered to be one of the evidence based procedures to prevent postoperative surgical infections, although a recent systematic review suggested that in the early studies its value might have been overestimated especially in the developed countries. ${ }^{1}$ In this study we have tried to see the outcome of the implementation of the checklist by monitoring the surgical site infection in cases with and without the use of the checklist and its compliance during the study.

Sentinel events continue to occur even in the United States. Their national incidence rate of wrong-patient, wrong-procedure, or wrong-site surgery is estimated to be as high as 50 per week. $^{2}$ The rate of major complications after surgery has been estimated at $3-17 \%$ which include wrong patient/procedure/site surgery, problems with anaesthesia equipment, unavailability of necessary equipment, unanticipated blood loss, non-sterile equipment, and surgical items (eg, sponges) left inside patients. ${ }^{14}$ During our study we did not experience any sentinel events. Checklists may reduce errors by many ways, as they ensure all critical tasks are carried out, encourage a nonhierarchical team-based approach, enhance communication, catch near misses early, anticipate potential complications, and have technologies to manage anticipated and unanticipated complications. ${ }^{14}$

Outcome benefits of the SSC demonstrated in formal studies are not achieved simply by SSC adoption unless there is careful attention to maximizing compliance. ${ }^{15}$ Compliance is defined by implementation quality, measured prospectively by the fidelity to actual use of the SSC with all 3 parts of the checklist. ${ }^{16}$ The checklist is considered fully completed when all the 24 items in the modified WHO checklist are filled, partially completed when at least one of the 24 items in the checklist is filled and not completed when none of the 24 items is filled. ${ }^{3}$ It was compared with each other in terms of emergence of SSI in this study. Here it was found that, SSI was less in cases with full compliance compared to partial compliance as shown by chi square test which was significant as $P$ value was $<0.05$.

The degree of compliance among health care workers, with various components of the checklist, is responsible for its success. ${ }^{17}$ Studies indicate that when all stages of the checklist are completed, $14 \%$ of complications can be prevented, and odds of experiencing a complication reduce by up to $43 \%$. $^{7}$

Importance of the value of the checklist and further strengthening of the implementation process are demonstrated by the objective outcomes such as reduction in mortality or surgical site infection rate. ${ }^{6}$

In a study by W-Dahl et al, after checklist implementation and appropriate timing of antibiotic prophylaxis, the infection rates decreased by $50 \% .{ }^{18}$

The most common cause of serious surgical complication is SSI. Antibiotic prophylaxis within the hour before incision and effective sterilization of instruments are inconsistently followed, as shown by the evidence not because of the cost or lack of resources but because of poor systematization. Antibiotics are often administered too early, too late, or simply erratically during peri-operative period, in both developed and developing countries, which make them ineffective in reducing patient harm. ${ }^{12}$ A publication by Weber et al included 3836 general surgical procedures; the greatest risk reduction occurred when antibiotics were administered between 30 and 60 minutes prior to the incision. ${ }^{2}$ A study by Vries et al has shown that the use of a similar checklist leads to better compliance with regard to the timing of antibiotic prophylaxis administration leading to better control of SSIs. ${ }^{4,12}$ In our study, the prophylactic antibiotics were given within 60 minutes of surgery in all cases where checklist were used. In those cases without the checklist, antibiotics were given as per hospital protocol just before the surgery. 
Yuan et al reported that two Liberian hospitals found checklist introduction was significantly associated with fewer surgical site infections (adjusted OR (AOR) 0.28 ; 95\% CI 0.15 to 0.54 ) and surgical complications (AOR 0.45; 95\% CI 0.26 to 0.78).(19) Similarly in our study, the cases with SSC had fewer SSI than those without the checklist as shown by OR 0.78 (95\% CI 0.45 -1.37).

The WHO SSC has been implemented worldwide as a standard of care in thousands of operating rooms since a multinational 3-month observational study reported a significant reduction in postoperative complication and mortality rates with the use of the checklist $(11-7 \%, \mathrm{p}<0.001$ and $1.5-0.8 \% \mathrm{p}=0.003$, respectively). ${ }^{20}$

Even if a properly performed checklist takes a greater time to conduct, the potential|decrease in delays outweighs the extra seconds that fidelity may require. ${ }^{21}$

In conclusion, implementation of the SSCL helps in reducing the morbidity and mortality when followed with full compliance. There are still hurdles to cross to get full compliance

\section{REFERENCES}

1. de Jager E, McKenna C, Bartlett L, Gunnarsson R, Ho YH. Postoperative Adverse Events Inconsistently Improved by the World Health Organization Surgical Safety Checklist: A Systematic Literature Review of 25 Studies. World J Surg 2016; 40: 1842-58.

2. Cabral RA, Eggenberger T, Keller K, Gallison BS, Newman D. Use of a Surgical Safety Checklist to Improve Team Communication. AORN J 2016; 104: 206-16. Available from: http://dx.doi. org/10.1016/j.aorn.2016.06.019

3. Chaudhary N, Varma V, Kapoor S, Mehta N, Kumaran V, Nundy S. Implementation of a Surgical Safety Checklist and Postoperative Outcomes: a Prospective Randomized Controlled Study. J Gastrointest Surg 2015; 19: 935-42.

4. VerweyS, Gopalan PD.Aninvestigation ofbarriers to the use of the World Health Organization Surgical Safety Checklist in theatres. S Afr Med J 2018; 108: 336-41. Available from: http://www. ncbi.nlm.nih.gov/pubmed/29629686

5. Hannam JA, Glass L, Kwon J et al. A prospective, observational study of the effects of implementation strategy on compliance with a surgical safety checklist. BMJ Qual Saf 2013; 22: 940-7.

6. Lilaonitkul M, Kwikiriza A, Ttendo S et al. Implementation of the WHO Surgical Safety in our part of the world. When applied with full compliance, the outcome is improved as shown by decrease in SSI. The difference SSI in two group is not significant in this study, which might be due to small sample size and a single center study. Further studies with bigger sample size in multiple centers can give higher significance. The confounding factors like the types of surgery emergency/ elective does have effect in the outcome. Fidelity in the implementation of the SSCL does have positive effect in the outcome despite being time consuming. An extra effort in complying to the checklist saves the life of the patient and avoids unwanted never events.

\section{ACKNOWLEDGEMENTS}

We would like to acknowledge Prof. Dr. Gautam Ratna Bajracharya, Head of Department of Anaesthesiology, NMCTH, for his continuous encouragement and guidance for this study and Dr. Gausan Ratna Bajracharya for his guidance and help in editing. Financial support from NMCTH for allocation of the grant for the research $(011-075 / 076)$ is gratefully acknowledged.
Checklist and surgical swab and instrument counts at a regional referral hospital in Uganda - A quality improvement project. Anaesthesia 2015; 70: 1345-55.

7. Kilduff CLS, Leith TO, Drake TM, Fitzgerald JEF. Surgical safety checklist training: A national study of undergraduate medical and nursing student teaching, understanding and influencing factors. Postgrad Med J 2018; 94: 143-50

8. de Vries EN, Dijkstra L, Smorenburg SM, Meijer RP, Boermeester MA. The Surgical Patient Safety System (SURPASS) checklist optimizes timing of antibiotic prophylaxis. Patient Saf Surg 2010; 4: 2-7.

9. Westman M, Marttila H, Rahi M, Rintala E, Löyttyniemi E, Ikonen T. Analysis of hospital infection register indicates that the implementation of WHO surgical safety checklist has an impact on early postoperative neurosurgical infections. J Clin Neurosci 2018; 53: 188-92. Available from: https://doi.org/10.1016/j. jocn.2018.04.076

10. Pugel AE, Simianu VV, Flum DR, Patchen Dellinger E. Use of the surgical safety checklist to improve communication and reduce complications. J Infect Public Health 2015; 8: 219-25.

11. Classen DC. The timing of prophylatic administration of antibiotics and the risk of surgical wound infection. N Engl J Med 1992; 326: 281-6. 
12. Shankar R. Implementation of the WHO Surgical Safety Checklist at a teaching hospital in India and evaluation of the effects on perioperative complications. Int'l J Health Plann Manage 2018; 33: 836-46.

13. Weber WP, Marti WR, Zwahlen M et al. The timing of surgical antimicrobial prophylaxis. Ann Surg 2008; 247: 918-26.

14. Treadwell JR, Lucas S, Tsou AY. Surgical checklists: A systematic review of impacts and implementation. BMJ Qual Saf 2014; 23: 299-318.

15. Hannam JA, Glass L, Kwon J et al. A prospective, observational study of the effects of implementation strategy on compliance with a surgical safety checklist. BMJ Qual Saf 2013; 22: 940-7.

16. Haugen AS, Wæhle HV, Almeland SK et al. Causal Analysis of World Health Organization's Surgical Safety Checklist Implementation Quality and Impact on Care Processes and Patient Outcomes. Ann Surg 2019; 269: 283-90

17. Rakoff D, Akella K, Guruvegowda C, Chhajwani S, Seshadri SK, Sola S. Improved Compliance and Comprehension of a Surgical Safety Checklist
With Customized Versus Standard Training: A Randomized Trial. J Patient Saf 2018; 14: 138-42.

18. W-Dahl A, Robertsson O, Stefánsdóttir A, Gustafson P, Lidgren L. Timing of preoperative antibiotics for knee arthroplasties: Improving the routines in Sweden. Patient Saf Surg 2011; 5: 22. Available from: http://www.pssjournal.com/ content $/ 5 / 1 / 22$

19. Yuan CT, Walsh D, Walsh JL, Alpern R, Shakpeh $\mathrm{J}$, Bradley EH. Incorporating the world health organization surgical safety checklist into practice at two hospitals in liberia. Jt Comm J Qual Patient Saf 2012; 38: 254-60.

20. de Jager E, Gunnarsson R, Ho YH. Implementation of the World Health Organization Surgical Safety Checklist Correlates with Reduced Surgical Mortality and Length of Hospital Admission in a High-Income Country. World J Surg 2019; 43: 117-24.

21. Anderson KT, Bartz-Kurycki MA, Masada KM et al. Decreasing intraoperative delays with meaningful use of the surgical safety checklist. Surgery (United States) 2018; 163: 259-63 